\title{
ESSAY
}

Invited article

DOI: http://dx.doi.org/10.1590/So034-759020160408

\section{TRANSNATIONAL REGULATORY INTEGRATION AND DEVELOPMENT: A NEW FRAMEWORK FOR INSTITUTIONAL CHANGE}

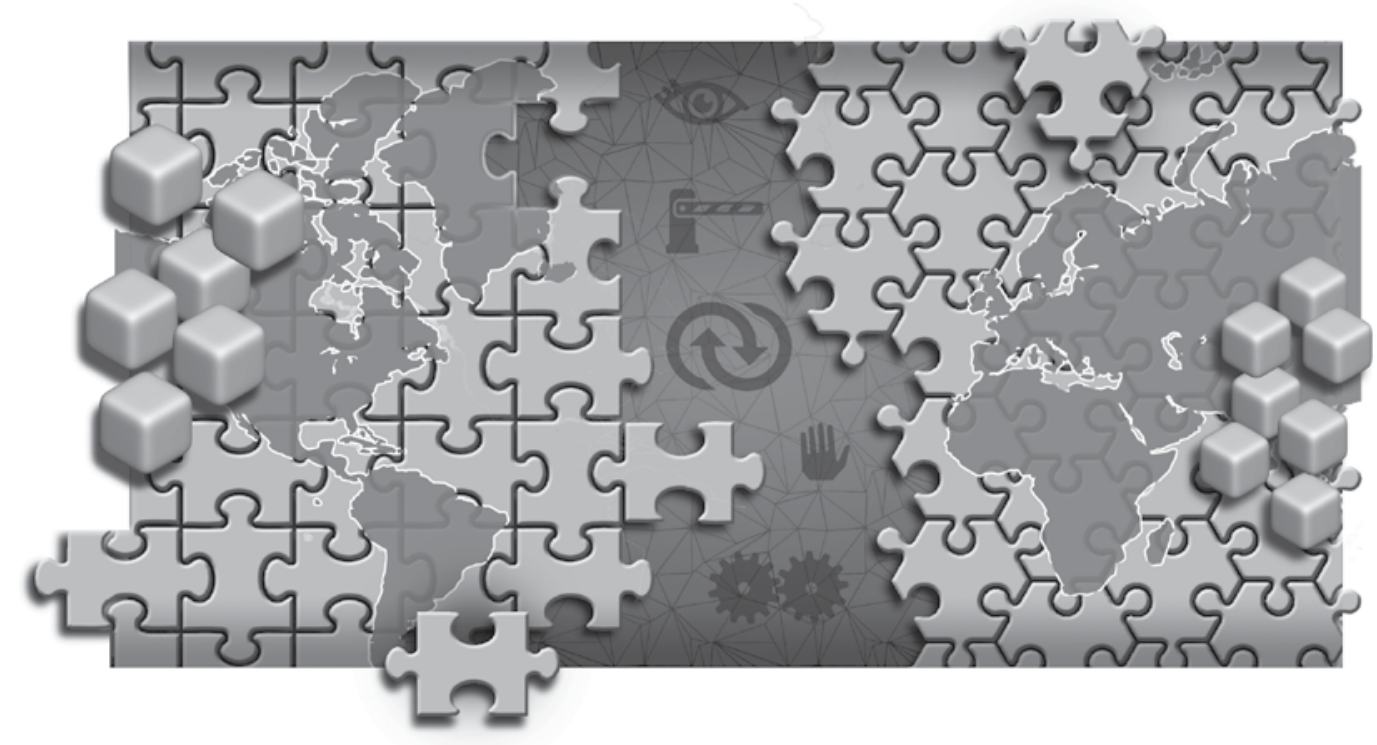

INTRODUCTION

It is increasingly evident that the creation of transnational markets is less a function of trade and financial liberalization and more a function of creating transnational regulations (Djelic \& SahlinAndersson, 2006; Jordana \& Levi-Faur, 2004). International organizations like the WTO, regional regimes like the EU, NAFTA, CAFTA or the Mercosur, and a host of non-state actors, including multinational corporations (MNCs) and international NGOs, attempt to create public and private regulations. Motivations vary: to integrate markets by harmonizing conflicting domestic regulations, to manage social or environmental externalities of more open markets, or simply to weaken competitors (Braithwaite \& Drahos, 2000). In turn, regulatory integration remains the locus of ongoing contestation by public and private actors that vary in their capacities to shape the definition of rules, the way they are implemented, and the distribution of their attendant costs and benefits.

This article examines how the extension of regulatory integration to developing countries

\section{LASZLO BRUSZT}

laszlo.bruszt@eui.eu

Professor at Institute of Humanities and Social Sciences, Scuola Normale Superiore - Firenze, Italy

GERALD A. MCDERMOTT

gerald.mcdermott@moore.sc.edu Professor at University of South Carolina, Darla Moore School of Business - Columbia - SC, USA and Universidad Austral, IAE Business School - Buenos Aires, Argentina affects the nature of these contestations and their outcomes both in terms of the spread of coordinated transnational regulations and in terms of their developmental outcomes. We use here the label 'developing' as shorthand for low- and middle-income countries outside of the core group of the most developed countries. The dramatic increase in attempts at regulatory integration involving less developed market economies brings a special twist into the patterns of contestation and the accompanying scholarly debates. The traditional concerns over transaction costs, social reproduction, and economic order are now linked to issues of differences in the capacities of advanced and developing countries to shape transnational rule making and benefit from the attendant redistribution of rights and obligations. As much as transnational regulatory integration could foster domestic institutional reforms in the developing world, it could as easily 
foster resistance and repellence (Braithwaite \& Drahos, 2008; Drezner, 2007). Indeed, as John Ruggie (1982) suggested more than thirty years ago, integration could leave the regime takers marginalized or drive the regime makers to adjust their goals and the way they use their powers.

We argue that transnational markets do not emerge in a sustainable fashion by merely liberalizing trade or by imposing the same rules on countries at different levels of development. Rather, integration strategies can vary in their ability to decrease the negative developmental consequences of transnational regulations and increase the positive ones. The strategies that aim to create sustainable common rules should make transnational rules a common good Such strategies have to face the problem of the differences in domestic institutional conditions that prevent many private and public actors in less developed countries from implementing and benefiting from new transnational rules. While actors in more developed and more powerful countries might gain from finding ways to link the issue of transnational regulatory integration with concerns about development, the transnational institutions that could help solve the attendant coordination problems are often not present.

Our framework (Bruszt \& McDermott, 2014) takes as its starting point the sharp variation of outcomes of transnational integration attempts within and across regions, policy domains and economic sectors. This framework helps explain the variation among developing countries in two ways. First, by bringing to the forefront the seemingly distinct literatures on development and the mediating roles of regional regimes, we compare the conditions under which attempts at transnational regulatory integration are more or less sustainable. Second, our framework helps to identify dynamics - how different approaches to integration can alter or conserve regulatory quality and the distribution of its benefits.
Building on research about transnational public and private regulation (Bartley, 2010; Locke, 2013; Mattli \& Woods, 2009), we note how pre-existing transnational and domestic institutional conditions can vary and shape the starting opportunities for the actors participating in transnational rule making. We also argue, however, that many initial outcomes represent unstable equilibriums, even when entrenched, powerful actors block or manipulate reforms for their own benefits. Rather, the inclusion and empowerment of diverse domestic private and public actors their embedding in a multiplex network of transnational supporting and monitoring institutions - can dramatically improve the success of regulatory integration and its developmental effects (Bruszt \& McDermott, 2012). The more complex the interactions among diverse actors with potentially conflicting interests and beliefs, the harder it is to create comprehensive solutions without the use of strategies that prefer joint problem solving and recursive learning (Sabel \& Zeitlin, 2009). Strategies that broaden the range of interlinked, regulatory change-related issues and organize negotiations and agreements around a bundle of policies at the inception can better associate diverse interests and create longer lasting settlements (Bruszt \& McDermott, 2012).

The next section offers a typology of domestic outcomes of regulatory integration attempts according with the enforcement of international standards and their distributional effects. The following sections offer an analytical framework to explain the variation in these outcomes and potential paths of change.

\section{MAPPING OUTCOMES OF REGULATORY INTEGRATION ATTEMPTS}

Regulatory institutions are mechanisms that coordinate diverse interests in order to extend economic transactions and cope with their related externalities. Transnational regulations include rules and standards derived from purely inter-governmental and regional agreements as well as those derived from domestic and external private actors (e.g., firms and NGOs) that may or may not be codified and enforced by national or supranational level public actors (Djelic \& SahlinAndersson, 2006).

Transnational regulatory integration is the process by which public and private actors from different countries attempt to create and implement common rules or standards that govern cross-border transactions and their potential positive and negative externalities. It aims at bringing convergence in norms, rules and policies across countries (Sweet \& Sandholtz, 1997). Deepening integration means extending normative convergence from a limited regulatory framework, such as for basic trade, to a more complex one, including regulations in various noneconomic domains. Regulatory fragmentation occurs when integration results in multiple conflicting rules within the same sector, policy field or territorially bounded market.

We move beyond the typical transnational regulation literatures by capturing both failed integration attempts and their developmental consequences. We classify four ideal types of outcomes according to two dimensions. The first dimension assesses the degree to which transnational rules are adopted into law and enforced domestically. For the sake of simplicity, no enforcement includes not adopting the rule and adopting it only on the books but not enforcing it. The second dimension is the degree to which the successful or failed integration attempt benefits a relatively broad or narrow set of domestic constituents in developing countries. At its most basic level, this variable captures the distribution of firms and firm stakeholders that may or may not be able to create the organizational capacities necessary to stay in the market and gain greater value-added opportunities (Bartley, 2010; Locke, 2013) 
The combination of these two dimensions reveals four ideal types of outcome as presented in Exhibit 1. In Outcomes 1 and 2, regulatory integration attempts succeed in bringing about common, enforced rules or standards in a particular domain. They differ, however, in their distributive effects, namely whether a broad or narrow group of firms has the capacities to implement the standards.

Outcome 1 occurs when the transnational rules are enforced and implemented in ways that benefit a broad constituency in the relevant industry or domain domestically. This is akin to Mattli and Woods' (2009) "common interest regulation". Some of EU's new, postcommunist member countries are reaching this outcome in a variety of domains, such as food safety or environmental protection, in that they are growing able to monitor and enforce rules and help many firms to implement the new standards.

Outcome 2 is "transnational regulatory capture" and often occurs when a dominating external actor succeeds in imposing transnational rules that imply a highly asymmetrical distribution of the costs and gains of regulatory change (Mattli \& Woods, 2009). Here the country adopts and enforces the new international rules, but only relatively few firms can actually implement it. Common to Mexico via the NAFTA and the initial stages of EU accession for post-communist countries, it is an outcome in which few firms can partake in the economic benefits of the more sophisticated markets, or few stakeholder groups can benefit from a rule that would potentially improve their working or environmental conditions (see chapters in Bruszt \& McDermott, 2014.)

In Outcomes 3 and 4, attempts at creating a common set of enforced laws across the relevant countries have failed, but the outcomes differ in terms of their distributional effects. Outcome 3 can be called "resistance" when the rules are not adopted but there remains a preservation of benefits to a broad constituency, such as in the defeat of the Multilateral Agreement on
Investment. Outcome 4 can be called "low equilibrium stasis," when transnational rules are not adopted and the skewed distribution of benefits in the relevant domain remains. This results in the preservation of the status quo with little integration of standards and limited advances in changing domestic institutions.

Outcomes 3 and 4 are arguably the most common in South-South arrangements. Resistance to international rules can often begin as appearing to fit in Outcome 3, i.e., protecting local producers and groups from rules that would create immediate significant disadvantages for their survival. For instance, Jordana and Levi-Faur (2005) have also shown how domestic interests in Latin America thwart regulatory models promoted by European and US MNCs. Failed attempts at formal regulatory integration do not necessarily mean that integration is completely blocked or reversed, but it is less clear whether the distribution of benefits and upgrading might expand, particularly with private regulations only. With the Mercosur notoriously unable to implement common legislation (Duina, 2006), some private actors may be strong enough to initiate cross-border voluntary regional standards in particular industries, like automotive, dairy, and grains (Costa \& Jacoby, 2014; Lengyel \& Delich, 2014). But relying on private regulations is usually unsustainable as it benefits only the few actors in control of entry to domestic or crossborder markets, which would thus be closer to Outcome 4 (Bartley, 2010; Locke, 2013).

The four ideal types can help us locate cases that, at some point in time, can be navigating between two outcomes or stuck in a sphere of fragmentation. These types can lead one to consider the factors responsible for the divergence in outcomes and the strategies that could drive them towards a more stable, comprehensive regulatory integration with broad-based benefits. For instance, why do countries with similar levels of economic and institutional development vary in terms of their formal incorporation of transnational standards and distribution of benefits? How might one country or region shift from one outcome to another?

\section{Exhibit 1. Ideal types of outcomes of transnational regulatory integration attempts}

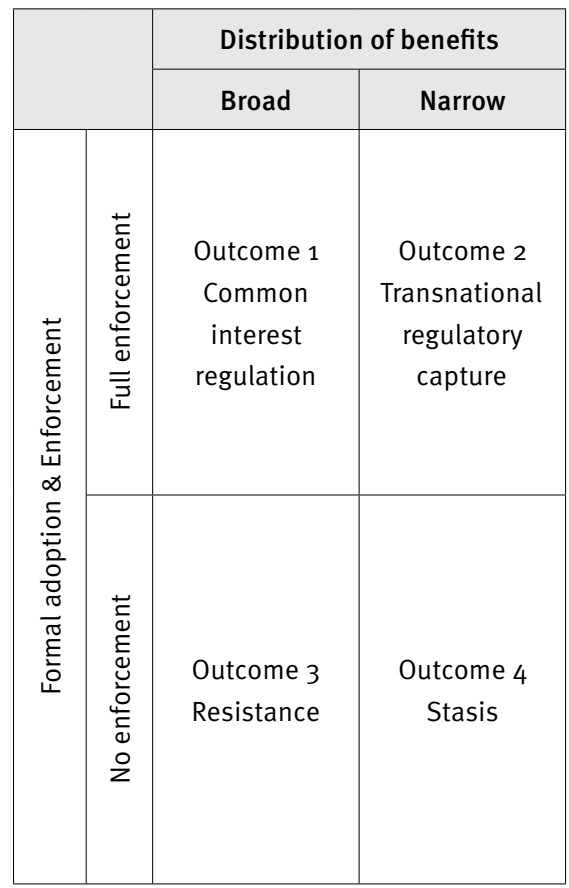

\section{EXPLAINING INITIAL OUTCOMES: DOMESTIC AGENCY AND TRANSNATIONAL PUBLIC POWER}

To answer these questions, our analytical framework offers static and dynamic analyses. The static analysis presented in this section considers diverse initial conditions particular to developing countries that could define the most likely initial outcomes of regulatory integration attempts as well as the strategic dilemmas of regulatory change in dramatically different local and transnational contexts.

First, developing countries often lack the institutional capacities necessary to define and implement rules, while diverse state and non-state actors lack the organizational capacities to promote and access certain information and ideas (Abbott 
\& Snidal, 2001). Many of these countries do not have the resources and capacities to capitalize on the opportunities of regulatory integration, let alone monitor and manage the developmental effects of the attendant rules (Stiglitz \& Charlton, 2006).

Second, many developing countries are either already integrated or in the process of integrating themselves into regional, public multidimensional regimes. These regional Transnational Integration Regimes (TIRs), such as NAFTA, CAFTA, Mercosur, and EU accession and neighborhood agreements, have their own mediating effects on transnational rule creation and adoption regardless of industry domain (Bruszt \& McDermott, 2012). Countries with similar initial domestic conditions but embedded in different TIRs can vary as to how they link transnational rules from one domain to another or how they link rule implementation with the recognition of claims from different actors.

In turn, we specify the two dimensions that account for domestic and transnational institutional conditions (See Figure 1). The first dimension, represented in the continuum of the vertical axis, considers the relative strength of domestic agency in emerging market countries. Domestic agency refers to the capacities of domestic actors to define, implement and enforce transnational rules. A relatively strong domestic agency (moving from low to high) allows domestic actors to adjust transnational rules to domestic needs, and/or adjust domestic institutions to the requirements of transnational rules. It also allows them to cope with the attendant negative developmental externalities and to broaden the range of local actors that could benefit from the process. In sum, the strengths and weaknesses of private and public actors are strongly interlinked in shaping domestic development agency in most cases. At the low end, relatively weak public capacities can result in state actors' inability to enforce new rules, anticipate or mitigate their potential negative developmental consequences, and support a variety of non-state actors' capacities to implement them. Many non-state groups can also lack the organizational capacities necessary to promote different claims and regulatory models, while a few resource-rich, entrenched actors can have the capacities to advance their own private standards.

Figure 1. Regional institutional capacities

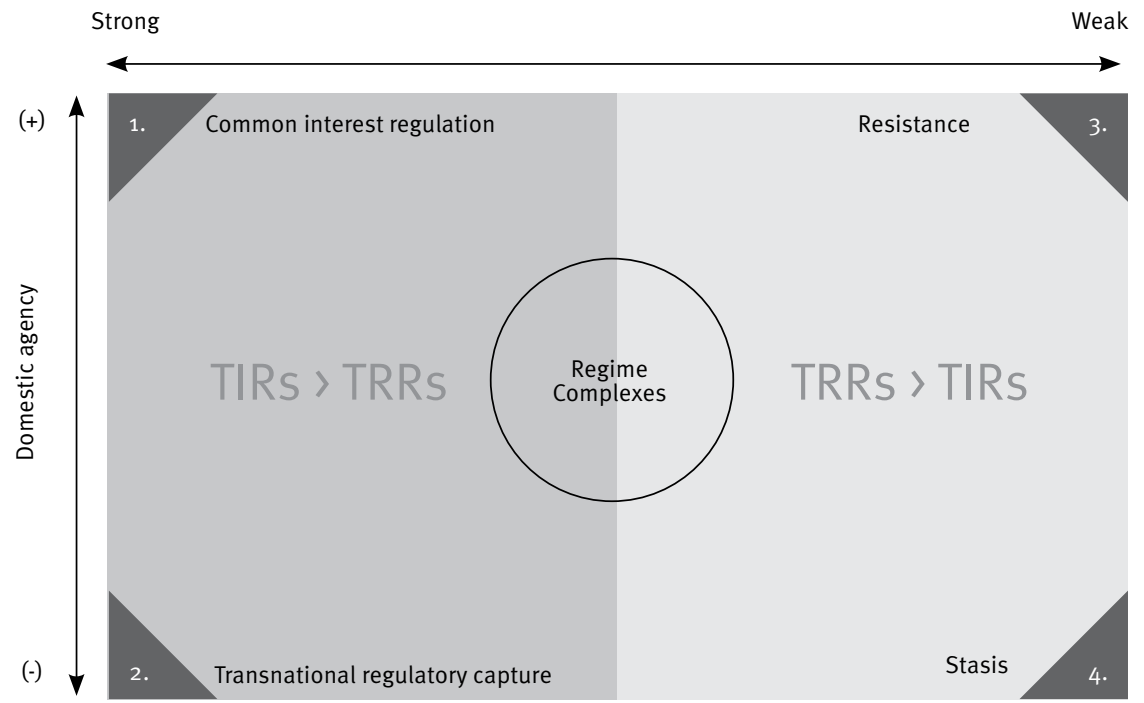

Our second dimension, on the horizontal axis, considers the regional transnational public capacities to create and sanction binding rules as well as solve the attendant collective action problems in various local contexts. Moving from left to right, regional TIRs vary in the degree to which they are based on significant political and economic power asymmetries (e.g., a hegemon) or based on more balanced - if not fragmented
- power structures that allow greater room for member vetoes and self-protection. Transnational hierarchies can be better able to define and impose rules and ensure compliance via side payments, but they rarely create lasting regulatory institutions (Abbot \& Snidal, 2001; Suwa-Eisenmann \& Verdier, 2007). Rather, TIRs can be more or less capable to assist domestic actors in improving their institutions in order to enable compliance and manage the attendant negative externalities of the new rules (Bruszt \& McDermott, 2012; Orenstein, Bloom, \& Lindstrom, 2008). Towards the right side of the figure, transnational settlements result in common rules solely at the level of specific sectors or policy areas. Towards the left side, regional arrangements are able to integrate national economies that might have prior conflicting regulatory systems. 
Hence, towards the left side of the figure, we can see the world of regional TIRs with hegemons, but with different transnational public capacities. The EU stands out as not just the largest but also the one with the most significant capacities for regulatory convergence and for empowering institutional change in the post-communist countries of East-Central Europe. NAFTA and CAFTA also have hegemonic structures but with limited integration capacities. The emerging TIRs in Latin America, East Asia, and Africa would be on the right side of the figure as they lack a capable hegemon and the capacity to coordinate and/or impose regional regulatory norms. In this world, TIRs are less coherent and have a limited ability to mediate the seemingly dominant industry or to issue specific transnational private regulatory networks, often known as Transnational Regulatory Regimes (TRRs) (Jordana \& Levi-Faur, 2005).

Combining the two dimensions can yield several dramatically different institutional contexts of regulatory integration attempts. On the four corners of Figure 1 are the four ideal typical outcomes discussed earlier. On the upper left corner is Outcome 1, which emerges from the combination of, on the one hand, relatively strong domestic public and private capacities for domestic agency, and, on the other, a TIR with strong public capacities. The more advanced stages of integration of some of the most developed East-Central European countries are moving towards this outcome as well.

Outcome 2 is on the bottom left corner and it is a combination of, on the one hand, weak domestic agency, and, on the other, a strong regional hegemon with limited capacities to produce regional public goods. The initial stages of the regulatory integration of East-Central Europe and the integration of Mexico into NAFTA would be closest to this corner.

On the upper right corner, we have Outcome 3. The combination of a relatively strong domestic agency and the absence of a regional hegemon provides for a context in which domestic actors might have the capacity to block the imposition of non-beneficial rules, but they lack the transnational institutional environment that could help them advance coherent attempts at regional rule harmonization. Transnational coordination is then more likely to be limited to attempts at relatively narrow private regulatory integration by well-organized sectors and by MNCs, such as in the Mercosur. The lower right corner represents Outcome 4, the least congenial institutional context for regulatory integration, with the combination of a very weak domestic developmental agency and a TIR with fragmented power and no public capacities.

The only truly stable settlements are on the upper left corner, where domestic and external actors have both the incentives and the capacities to reproduce the status quo. Outside of this corner are various institutional contexts in which there are significant weaknesses in institutional capacities and/or developmental outcomes. In turn, key groups can have strong incentives and opportunities to alter the parameters of their context and employ strategies that can move outcomes away from an unstable balance. We will discuss these conditions and strategies in the next section.

Figure 2 provides a few examples in a variety of intermediate spaces, including indications of paths of movement between outcomes. On the left side, TIRs have a relatively stronger impact on rule-taking countries than TRRs. TIRs provide the key architecture for transnational private and public actors to alter the domestic socioeconomic and institutional conditions in rule-taking countries and potentially move these countries upward. Examples

\section{Figure 2. Regional institutional capacities}

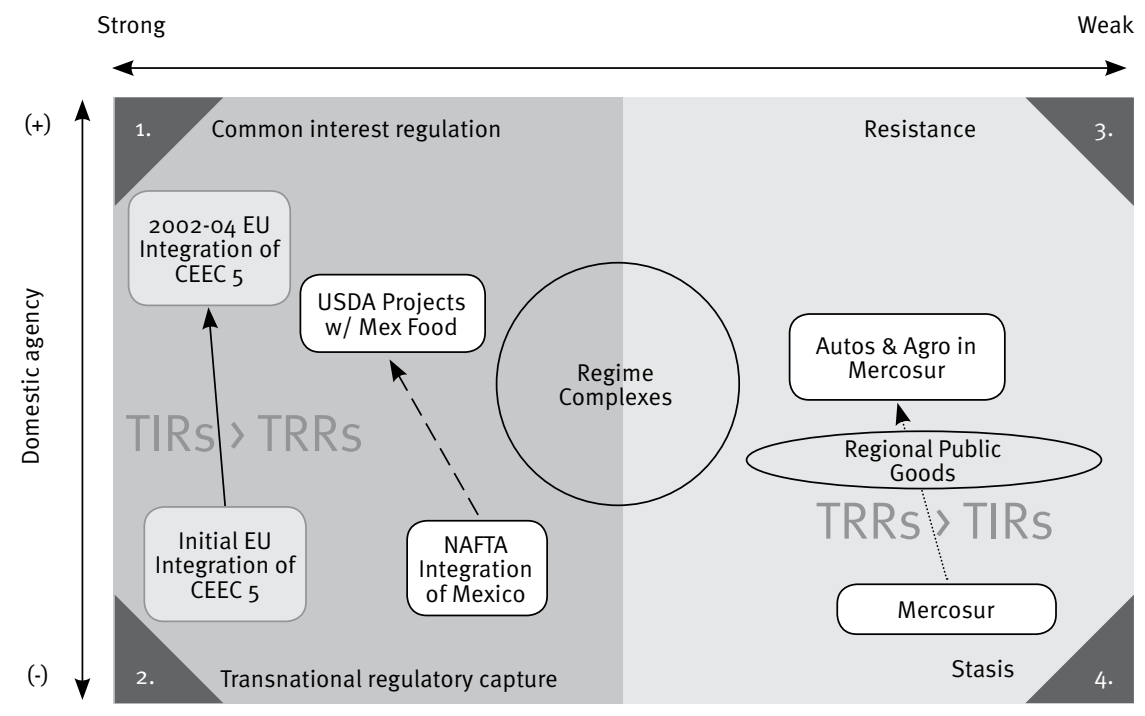


of this can be the EU's complex institutionbuilding programs in countries in Eastern and Central Europe applying for an EU membership, or, in a much more limited way, a few programs on food safety and the environment in Mexico and Central America. (see chapters in Bruszt \& McDermott, 2014.)

In the space between the lower and upper right corners, there are no regional TIRs that could help public and private actors to solve complex problems of coordination. Attempts at regulatory integration can have a weakly defined territorial dimension and are more sector- or domain-based, allowing TRRs to multiply and fragment markets, such as the attempts by industry-based networks, like telecoms in Latin America, and autos and agriculture in the Mercosur. Possibilities for broader regulatory harmonization and improved domestic agency more often than not come from institutional bootstrapping strategies initiated by transnational networks of business associations, MNCs, NGOs and governments. Typical examples are the regional public goods programs supported by the Inter-American Development Bank for creating new regional systems of infrastructure and standards while improving relevant domestic capacities (Estevadeordal, Frantz, \& Nguyen, 2004).

\section{THE DYNAMICS OF INTEGRATION STRATEGIES AND DOMESTIC DEVELOPMENTAL AGENCY}

Since many of the above initial outcomes of transnational integration are suboptimal and unstable, a key issue is how to identify the mechanisms that facilitate improvement - the dynamics of integration. Here we analyze how different integration strategies can improve domestic development agency and, in turn, provide the basis for trans national regulatory arrangements that are more encompassing and sustainable. We argue that moving towards regulatory ar- rangements that decrease the fragmentation of transnational markets and increase the scope of common rules implies seeking ways to upgrade domestic agency that could domestically increase the potential benefits of incorporating transnational rules while decreasing their potential negative consequences. The more complex the domestic institutional problems, the greater the need for assisting domestic institutional change, including via external intervention, the latter requiring transnational institutional capacities that, in most cases, are not at hand. Assembling transnational markets via common rules thus involves the dilemma of how to upgrade domestic institutions while creating transnational capacities to successfully govern domestic change.

To better understand the structural and political roots of this dilemma, one should distinguish between the demand and supply sides of domestic institution building (Bruszt \& McDermott, 2012). On the demand side, public and private actors that might have an interest in regulatory change often lack the resources and channels to gain sustained attention from the state. Entrenched groups maintain the status quo not only because they profit from it, but also because there are no comprehensive structures to facilitate horizontal ties for weaker groups, which could open new possibilities for experimentation and extend time horizons (Tendler, 1997).

On the supply side, states often lack the capacity necessary to coordinate institutional upgrading, while many nonstate actors lack the material and knowledge resources necessary to undertake their own initiatives (McDermott, 2007). Adaptation and enforcement of transnational rules in local contexts, as well as enabling local actors to benefit from these rules, require specific state capacities. But the state ex ante often lacks the requisite skills, knowledge, or resources, and, in turn, must coordinate the process with a variety of stakeholder groups who, combined, have complementary resources and information. At the same time, the benefits of this coordination can be sacrificed if the groups lack the power and processes with which to contest each other's claims or models (Evans, 2004; Tendler, 1997).

Notice that emphasizing blockage to both institutional change and regulatory integration in these terms, rather than, say, pointing to pure state capture or culture, highlights some core institutional change governance dilemmas for an external actor - whether it is a MNC, a multilateral agency or a regional hegemon. One such dilemma is that without a dedicated empowerment of various key public and private (often weaker) actors, the benefits and sustainability will be limited. Another is that the large number of different combinations of demand- and supply-side constraints can limit a universal solution or design while demanding a flow of information for external actors to adapt their approaches and coordinate efforts to specific contexts.

In turn, assembling transnational markets via common rules must take account of these dilemmas when trying to improve domestic agency while simultaneously creating the supranational capacities to effectively govern this process. This problem is reflected in our Figure 2. Moving towards more encompassing common rules, we argued, implies upgrading domestic developmental agency, thus changing institutional parameters along the vertical axis. More often than not, such a movement presupposes change in the capacities of the transnational actors who want to induce domestic institutional change, thus involving a simultaneous movement along the horizontal axis. This latter point may not be directly obvious, as it goes beyond the mere overt power and incentive packages provided by the external actors. For instance, as we noted earlier, even if a TIR has the capacity to impose externally invented solutions, it might have weak capacities to detect why certain solutions have worked or 
not, and how it could coordinate, assist, and monitor institutional change in a variety of local contexts.

We now highlight specific goals and means of integration strategies that can facilitate or impede changes in domestic developmental agency and hence move away from the suboptimal initial outcomes represented in Figure 2. We can compare the various strategies based on two components of their goals and two components of their means. The former are the scope and depth of the goals of institutional change. The latter are whether monitoring and assistance are dyadic or multiplex and the degree to which they are based on principles of checklist compliance or joint problem solving. Figure 2 shows the different paths and mixes of these components in the cases we studied.

Scope refers to the different policy domains in which regulatory integration attempts require institutional changes from the participant countries. It can be rather narrow, i.e., focusing on a few economic trade rules, or quite extensive, i.e., reaching social and political domains. While narrow goals could lead to spillover effects in other domains, broader goals can potentially incorporate a variety of stakeholder groups at inception, offering them opportunities to shape and own reforms.

Depth refers to the emphasis placed on building different types of domestic capacities. Most often, goals are shallow, with an emphasis simply on changes in rules, based on an often misplaced assumption that a rule change will trigger sustained mobilization and institution building. In contrast, a relatively greater depth means improving the capacities to enforce and monitor new regulations (Schimmelfennig \& Sedelmeier, 2005; Stigliz \& Charlton, 2006)

The means of integration consist of assistance (i.e., resources) for the target country so it can meet the defined goal, and monitoring the degree to which the country meets its goals. These means vary not simply in size or quantity but especially according to two qualitative components - the structure of transnational horizontal relationships and the nature of information feedback loops.

The first component is the degree to which the interactions between relevant external and domestic actors can be dyadic, involving solely two institutional actors (e.g., state to state), or multiplex, including a variety of public and private actors to create ongoing professional relationships (Padgett \& Ansell, 1993). Integration strategies that promote mainly dyadic relationships often assume that general economic and political incentives will foster transnational relationships between peer groups or actors. In contrast, other integration strategies purposively support multiplexity by using legal triggers and resources to foster transnational relationships among a variety of groups relevant to the domain, such as NGOs, associations, firms, and subnational governments. Promoting multiplexity offers external actors a greater variety of information and experiments related to domestic changes, while many domestic actors are empowered via new alliances, resources, and knowledge (Andonova, 2004; Jacoby, 2004). For both sides, if the transnational horizontal linkages have a relatively greater multiplexity, then it is less likely for there to be a single gatekeeper in a developing country controlling resources, contacts, and information about a given policy domain.

The second component is the relative emphasis on checklist compliance or joint problem solving, denoting the ways in which the relevant external and domestic actors share and analyze information within and across policy domains to find shortcomings and how to address them (Carothers, 2003; Easterly, 2006; Sabel \& Zeitlin, 2009). Feedback via checklist compliance means that information is used simply to determine whether a country meets the designated goal, but not much else. This assumes that such findings would be an incentive for the relevant domestic actors to take corrective action. Feedback via joint-problem solving principles emphasizes the need for the relevant external and domestic actors to evaluate shortcomings with the aim of generating alternative solutions to be followed. Even if assistance and monitoring criteria are non-negotiable and inflexible, repeated information about why the country is falling short in one domain can drive deliberations in several directions, such as revising the sequence of steps within the domain, altering the type of assistance being delivered, or targeting resources towards groups that are better suited to undertake the given reform (Jacoby, 2004; Vachudova, 2005). When multiplexity and joint problem solving are combined, they can greatly improve accountability and legitimacy among all parties as they join a "community of practice" that instills ownership and adherence to common norms (Bartley, 2010).

The combinations of these goals and means can help us compare and contrast transnational integration strategies and evaluate their resulting paths of change, such as the ones presented in Figure 2. First, moving up and to the left in Figure 2 points to the context of integration strategies that place a relatively strong emphasis on broad-based capacity building in their goals and on multiplexity and joint problem solving (e.g., the EU accession process). In contrast, weaker outcomes (e.g., Mexico in NAFTA) seem to remain where integration strategies emphasize goals that are narrow and shallow combined with means that stress dyadic ties and check list compliance principles. Second, integration strategies often vary as to their combination of components, and pilot projects can lead to broader changes in regulatory regimes. For instance, many attempts at moving away from the status quo and upwards on the right side of Figure 2 (e.g., autos and agriculture in the Mercosur) are initiated by non-state actors in a particular industry or domain with rather narrow goals, but they make progress by emphasizing capacity building and joint 
problem solving. Such results also suggest how key public and private actors in different domains are discovering more or less optimal combinations of goals and means, and, in turn, are being faced with promoting further significant experiments in the governance of TIRs and TRRs. Indeed, despite the weakness of NAFTA's institutional capacities, progress in implementing international food safety and environmental standards for a broader number of stakeholders appears to emerge from a focus on capacity building via jointproblem solving and multiplexity (Aspinwall, 2014; McDermott \& Avendano, 2014)

\section{CONCLUDING REMARKS}

If the recent global financial crisis has taught us anything, it is that the transnationalization of markets is fraught with fragility, which makes domestic institutional development so much more contingent on the interaction between local and foreign approaches to regulatory integration. In opening their economies to accelerate growth and upgrade their capabilities, societies of the developing world have known this all too well. The framework presented here tries to define the contours of this contingency by linking the approaches to transnational regulatory integration with the domestic process of institution building in emerging market countries. First, we showed how these countries face different types of political constraints due to both domestic variation in institutional capacities and the supranational regimes in which they find themselves increasingly embedded. But these factors are not static or immutable. As our framework suggests, different combinations of the goals and means of TIRs and TRRs can reify or reshape the constraints and opportunities that domestic and external actors face as they forge distinct paths of transnational regulatory integration and domestic regulatory renovation.

In combining advances in comparative and international political economy, the approach advanced here makes two basic claims. First, sustained regulatory integration depends in large part on the capacities of domestic public and private actors to incorporate, adapt and implement international rules and standards at the formal regulatory level and at the firm or organizational level in a broad-based manner. The process of capacity building, however, can take different paths and cannot be read off a generic template and thus induced by arm's length incentives or a largess of foreign resources. Rather, it is a process of contestation and experimentation, in which public and private actors often recombine resources to experiment with new formal and informal regulatory models and challenge each other's claims about the attendant costs, benefits, and legitimacy.

Second, the variation in the goals and means of intersecting integration approaches can empower different public and private actors on the ground, hence shaping the process of contestation and experimentation at the local and regional levels. Rather than separating the external from the internal or the public from the private in tracking regulatory integration, scholars and policymakers should pay closer attention to the ways in which assistance and monitoring in integration approaches can stimulate or impede horizontal linkages, accountability and problem solving among a broader set of local and outside actors.

\section{AUTHORS' NOTE}

This article is based on our book, Leveling the playing field: Transnational regulatory integration and development (Bruszt \& McDermott, 2014).

\section{REFERENCES}

Abbott, K. W., \& Snidal, D. (2001). International 'standards' and international governance. Journal of European Public Policy, 8(3), 345370. doi:10.1080/13501760110056013

Andonova, L. B. (2004). Transnational Politics of the Environment: The European Union and Environmental Policy in Central and Eastern Europe. Cambridge, MA: MIT Press.

Aspinwall, M. (2014) The NAFTA Side Agreements and Governance in Mexico. In L. Bruszt \& G. McDermott (Eds.), Leveling the playing field: Transnational regulatory integration and development. Oxford, UK: Oxford University Press.

Bartley, T. (2010). Transnational private regulation in practice: The limits of forest and labor standards certification in Indonesia. Business and Politics, 12 (3), 1469-3569. doi:10.2202/1469-3569.1321

Braithwaite, J., \& Drahos, P. (2000). Global business regulation. Cambridge, UK: Cambridge University Press.

Bruszt, L., \& McDermott, G. A. (2012). Integrating rule takers: Transnational integration regimes shaping institutional change in emerging market democracies. Review of International Political Economy, 19(5), 742778. doi:10.1080/09692290.2011.619469

Bruszt, L., \& McDermott, G. A. (Eds.). (2014). Leveling the playing field: Transnational regulatory integration and development. Oxford, UK: Oxford University Press.

Carothers, T. (2003). Promoting the rule of law abroad: The problem of knowledge. Rule of Law Series [Working Paper No 34], Carnegie Endowment for International Peace, Washington, D. C.

Costa, M., \& Jacoby, W. (2014). The informal drivers of regional regulatory integration: The auto sector in Central Europe and Latin America. In L. Bruszt \& G. McDermott (Eds.), Leveling the playing field: Transnational regulatory integration and development. Oxford, UK: Oxford University Press.

Djelic, M.-L., \& Sahlin-Andersson, K. (2006). Transnational governance: Institutional dynamics of regulation. Cambridge, UK: Cambridge University Press.

Drezner, D. W. (2007). All politics is global: Explaining international regulatory regimes. Princeton, USA: Princeton University Press.

Duina, F. G. (2006). The social construction of free trade: The European Union, Nafta, and Mercosur. Princeton, USA: Princeton University Press. 
Easterly, W. R. (2006). The white man's burden: Why the west's efforts to aid the rest have done so much ill and so little good. New York, USA: Penguin Press.

Estevadeordal. A., Frantz, B., \& Nguyen, T. (Eds.). (2004). Regional public goods. Washington, USA: Inter-American Development Bank.

Evans, P. B. (2004). Development as institutional change: The pitfalls of monocropping and the potentials of deliberation. Studies in Comparative International Development, 38(4), 30-52. doi:10.1007/bfo2686327

Jacoby, W. (2004). The enlargement of the European Union and NATO: Ordering from the menu in Central Europe. Cambridge, UK: Cambridge University Press.

Jordana, J., \& Levi-Faur, D. (2004). The politics of regulation: Institutions and regulatory reforms for the age of governance. The $\mathrm{Crc}$ Series on Competition, Regulation and Development. Cheltenham, UK: E. Elgar.

Jordana, J., \& Levi-Faur, D. (2005). The diffusion of regulatory capitalism in Latin America: Sectoral and national channels in the making of a new order. The Annals of the American Academy of Political and Social Science, 598(1), 102-124. doi: $10.1177 / 0002716204272587$
Lengyel, M., \& Delich, V. (2014). Multiple paths toward regime building? SPS regulation in the MERCOSUR. In L. Bruszt \& G. McDermott (Eds.), Leveling the playing field: Transnational regulatory integration and development. Oxford, UK: Oxford University Press.

Locke, R. (2013). The Promise and Limits of Private Power: Promoting labor rights in a global economy. Cambridge, UK: Cambridge University Press.

Mattli, W., \& and Woods, N. (2009). The politics of global regulation. Princeton, USA: Princeton University Press.

McDermott, G. A. (2007). The politics of institutional renovation and economic upgrading: Recombining the vines that bind in Argentina. Politics and Society, 35(1), 103-143. doi:10.1177/0032329206297185

McDermott, G. A. \& Avendano, B. (2014). The Dual Paths of Transnational Integration and Institutional Upgrading for Mexican Food Safety. In L. Bruszt \& G. McDermott (Eds.), Leveling the playing field: Transnational regulatory integration and development. Oxford, UK: Oxford University Press.

Orenstein, M., Bloom, S., \& Lindstrom, N. (Eds.). (2008). Transnational actors in Central and East European transitions. Pittsburgh, EUA: University of Pittsburgh Press.

Padgett, J., \& Ansell, C. (1993). Robust action and the rise of the Medici, 1400-1434. American Journal of Sociology, 98(6), 1259-1319.
Ruggie, J. (1982). International regimes, transactions, and change: Embedded liberalism in the postwar economic order. International Organization, 36(2), 379-415. doi:10.1017/So020818300018993

Sabel, C. F., \& Zeitlin, J. (2009). Experimentalist governance in the European Union: Towards a new architecture. Oxford, UK: Oxford University Press.

Schimmelfennig, F., \& Sedelmeier, U. (Eds). (2005). The Europeanization of Central and Eastern Europe. Ithaca, NY: Cornell University Press.

Stiglitz, J. E., \& Charlton, A. (2006). Aid for trade. International Journal of Development Issues, 5(2), 1-41. doi:10.1108/ebo45861

Suwa-Eisenmann, A., \& Verdier, T. (2007). Aid and trade. Oxford Review of Economic Policy, 23(3), 481-507. doi:10.1093/oxrep/grmo28

Sweet, A. S., \& Sandholtz, W. (1997). European integration and supranational governance. Journal of European Public Policy, 4(3), 297 317. doi:10.1080/13501769780000011

Tendler, J. (1997). Good government in the tropics. Baltimore, USA: Johns Hopkins University Press.

Vachudova, M. A. (2005). Europe undivided: Democracy, leverage, and integration after communism. Oxford, UK: Oxford University Press. 